\title{
Three-dimension High-resolution Anorectal Manometry Can Precisely Measure Perineal Descent
}

\author{
Véronique Vitton, $^{1,2 *}$ Jean-Charles Grimaud ${ }^{1,2}$ and Michel Bouvier ${ }^{1,2}$ \\ ${ }^{1}$ Service de Gastroentérologie, Hôpital Nord, Assistance Publique-Hôpitaux de Marseille, Marseille, France; and ${ }^{2}$ Interface de Recherche \\ Translationnelle en Neurogastroentérologie, CRN2M, UMR 7286, Aix-Marseille Université, Marseille, France
}

A 65-year-old woman was referred to investigate a long history of intractable constipation. Clinical examination revealed a descending perineum and digital examination diagnosed a large rectocele without stool in the rectum. The patient underwent 3-dimension high-resolution anorectal manometry (3DHRAM), dynamic endo-anal ultrasonography (D-EUS) and conventional defecography. The 3DHRAM showed mean resting pressure of $84 \mathrm{mmHg}$, mean maximal squeezing pressure of $207 \mathrm{mmHg}$ and length of the high-pressure zone of $2.7 \mathrm{~mm}$. The recto-anal inhibitory reflex was present and the rectal sensitivity was normal $(10 \mathrm{~mL})$. However there was an incomplete anal relaxation during attempted defecation indicating a pelvic floor dyssynergia. In addition during attempted defecation a $9 \mathrm{~mm}$ perineal descent on the manometric probe was observed in the left lateral decubitus position (Figure). At the end of the bear down the perineum regained its initial position indicating that the probe has not moved. Conventional defecography showed a $9.2 \mathrm{~mm}$ perineal descent from the pubo-coccygeal line, a retentive rectocele of $69 \mathrm{~mm}$ and rectal intussusception. D-EUS showed no anal sphincter defect and, at dynamic time, showed a rectocele measured at $35 \mathrm{~mm}$ and descending perineum measured at $15 \mathrm{~mm}$ according to the method described by Vitton et al. ${ }^{1}$

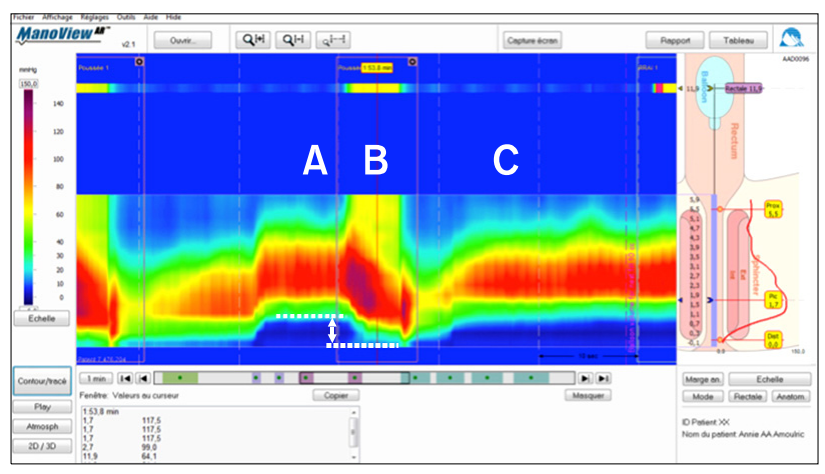

Figure. Result of the 3-dimension high-resolution anorectal manometry during the defecation effort. Before (A), during (B) and after (C) defecation effort. The row between the 2 dotted lines measures the size of the perineal descent. Note that in $\mathrm{C}$ the perineum regain its initial position (as in A).

This observation confirms that 3DHRAM can provide morphological data as reported by previous data. ${ }^{2-5}$ Here, for the first time, 3DHRAM demonstrated to diagnose precisely a perineal descent which was also diagnosed by conventional defecography suggesting that the position of the patient during the procedure might not be such an important determinant of pelvic floor dis-

Received: November 20, 2012 Revised: January 20, 2013 Accepted: January 24, 2013

(c) This is an Open Access article distributed under the terms of the Creative Commons Attribution Non-Commercial License (http://creativecommons. org/licenses/by-nc/3.0) which permits unrestricted non-commercial use, distribution, and reproduction in any medium, provided the original work is properly cited.

*Correspondence: Véronique Vitton, MD, PhD

Department of Gastroenterology, Hôpital Nord, Chemin des Bourrely, 13915 Marseille Cedex 20, France

Tel: +33-4-9196-5598, Fax: +33-4-9196-5550, E-mail: vittonv@yahoo.com

Financial support: None.

Conflicts of interest: None. 
order measurement.

\section{References}

1. Vitton V, Vignally $\mathrm{P}$, Barthet $\mathrm{M}$, et al. Dynamic anal endosonography and MRI defecography in diagnosis of pelvic floor disorders: comparison with conventional defecography. Dis Colon Rectum 2011;54:1398-1404.

2. Cheeney G, Remes-Troche JM, Attaluri A, Rao SS. Investigation of anal motor characteristics of the sensorimotor response (SMR) using
3-D anorectal pressure topography. Am J Physiol Gastrointest Liver Physiol 2011;300:G236-G240.

3. Cheeney G, Nguyen M, Valestin J, Rao SS. Topographic and manometric characterization of the recto-anal inhibitory reflex. Neurogastroenterol Motil 2012;24:e147-e154.

4. Lee TH, Lee JS. High-resolution Anorectal manometry for acquired megarectum in a patient with parkinson's disease. J Neurogastroenterol Motil 2012;18:218-219.

5. Lee TH, Lee JS. High-resolution anorectal manometry and anal endosonographic findings in the evaluation of fecal incontinence. $\mathrm{J}$ Neurogastroenterol Motil 2012;18:450-451. 